\title{
A REALIST ASSESSMENT OF THE IMPLEMENTATION OF BLENDED LEARNING IN A SOUTH AFRICAN HIGHER EDUCATION CONTEXT
}

\author{
M. A. Abrahams* \\ Division for Lifelong Learning. \\ e-mail: marka@iafrica.com
}

\section{S. Witbooi*}

Library and Information Sciences

e-mail: switbooi@uwc.ac.za

*University of the Western Cape.

Bellville, South Africa

\section{ABSTRACT}

Opportunities for further studies by working adults came under threat as the University of the Western Cape stopped the offering of after-hours classes in most of its Faculties. Unqualified and under-qualified librarians were directly affected by this decision. This article outlines an assessment of the conceptualisation and implementation of an action research project initiated by the Division for Lifelong learning. Using a realist evaluation approach, the assessment focuses on the implementation of strategies aimed at showing how lifelong learning opportunities, conceptualised and provided in flexible ways, could support innovation in learning and teaching in order to enhance access and success to learning by working people in the context of the Library and Information Science Department.

Key words: realist evaluation; higher education, blended learning; flexible learning and teaching, library science, lifelong learning, part-time studies, work and learning

\section{INTRODUCTION}

Confronted with the challenge of decreasing opportunities for working adults to study at the University of the Western Cape (UWC), the Division for Lifelong Learning (DLL) embarked on an action research project to engender flexible learning and teaching provision in three pilot sites at the university. UWC has since its inception in 1960 offered evening classes to working students. The increase of its intake of young full-time students, the ongoing pressure on staff to generate research and the unfolding of a strategic objective to promote post-graduate studies at the university are some of the factors that contributed to the decisions to limit its after-hours offering in some departments as well as to cease offering completely, as was the case in the Arts faculty where the Library Information Science (LIS) department is located. 
The myriad of components involved in the overall intervention alerted to the complex nature of the endeavour. The intervention was also steeped in explicit and implicit theoretical views that informed choices of definitions and the general discourse associated with the intervention. Even the framing of it as an action research process revealed a discursive treatment of the problem based on particular ideological assumptions. A realist assessment was deemed appropriate for this complex intervention where multiple interacting components were present; where components did not act in a linear fashion; where it was reliant on people to carry out the intervention and most importantly, it was highly dependent on the context in which it took place.

The action research project's research question for the various sites on campus and indeed the institutions was: 'What conditions need to change in order to give working people access to achieve success at UWC?' The specific evaluative research questions for the application of the intervention at the LIS site were:

- What was the overall nature of the intervention? - Context

- What factors/mechanisms hindered/ supported the intervention? - Mechanisms

- What were the experiences of students and staff? - Outcomes

- How/where/ to what extent did the intervention manifest as blended learning?

The multiple factors alluded to above, the varied project referents and the institution's very diverse student population (February and Koetsier 2007; Daniels and Roman 2013) informed the realist evaluation approach, one that is grounded in critical realism and asserts that both the material and social are 'real' and can have real effects. Pawson and Tilley's (1997) articulation of the close and dynamic interplay between a programme's context and mechanisms leading to outcomes, informed the choice of methodological approach for the assessment of the LIS intervention.

\section{METHODOLOGICAL APPROACH}

A common sense understanding of the purpose of programme evaluation is to find out what is and is not working in an intervention. Clarke and Dawson (1999) credit Scriven, for introducing the most popular organising conceptual framework for evaluation research in 1967. Scriven used the terms/concepts formative and summative to describe two approaches to programme evaluation and this distinction has characterised evaluation research for decades. Formative evaluation, as articulated by Scriven was employed to provide feedback to people who wanted 
to improve a programme or an intervention. The emphasis in formative evaluation is on the gathering of information from programme planners, practitioners and participants to assess what changes are needed to improve the programme. Summative evaluation on the other hand focuses on the determination of overall effect of the programme. In contrast to the improvement agenda of formative evaluation, summative evaluation is employed with the intention of making recommendations whether the programme should continue to run or not. Depending of the specific purposes of the evaluation, the context of the programme, and the needs of programme planners and implementers, an evaluator will make a choice for the type of evaluation to employ.

Rossi, Freeman and Lipsey (1999, 2) provide a more detailed definition of programme evaluation; 'The use of social research procedures to systematically investigate the effectiveness of social intervention programs that is adapted to their political and organizational environments and designed to inform social action in way that improve social condition'. In this definition, a simple experimental design - the black box design - runs the risk of focusing only on one aspect of this framework, that is, outcome assessment. The results of such a design provide answers to questions related to outcomes but are unable to shed much light on the reasons for the results, be they positive or negative.

Kazi $(2003,11)$ identifies those evaluation practices focusing solely on outcomes as emanating from an empirical practice paradigm and provides the following categorisation of evaluation practices as they are manifested in research paradigms:

\section{Empirical practice}

2. Pragmatism or methodological pluralism

3. Interpretivist approaches including critical theory and participatory approaches

4. Post-positivist approaches such as scientific realism.

He further states that a crucial limitation of empirical practice is its focus on effects or outcomes almost to the exclusion of the character and nature of the intervention that is being measured. It relies on the application of reliability and validity tests to deal with the limitation of understanding reality. This approach is embedded in a positivist ontological orientation to reality, according to Krauss (2005), where the researcher is regarded as separated from the world s/he is studying. The lack of analysis of the context in this approach makes replication difficult because social interventions involve the interplay of the individual and the social and multiple factors and influences are continuously at work (Kazi 2001). 
The pragmatic or pluralist approach embraces the advantages of empirical practice and attempts to compensate for its limitations through triangulation (Kazi 2003). This 'anything goes' approach has been critiqued as being anti-intellectual for failing to engage with epistemological debates. On the other hand, the mixed methods movement has managed to highlight the limitations of research methods associated with specific paradigms and put forward convincing arguments that it is acceptable to combine qualitative and qualitative methods to develop a more comprehensive approximation of reality. Ontologically, pragmatists tend to draw the line at relativism, and therefore, at least at the level of ontology, it is not 'anything goes' (Kazi 2003). Methodological pragmatists consider feasibility as the main criteria and tend to over emphasise the needs of stakeholders or the needs of practise and often fail to capture the effectiveness of a programme.

Interpretivist evaluation approaches include critical theory, social constructivism and feminist evaluation (Kazi 2003). There is a preference for qualitative methods that enable the researcher to dig deeper and the application of a dialogic approach to help participants achieve greater self-knowledge. According to Kazi (2003), the process of enquiry here is not technical or procedural but embedded in values, ethics, morality and politics. Similar to the pragmatist approach there is a tendency to exclude the consideration of outcomes and the concentration on in-depth processes lead to a lop-sided treatment of the main dimensions of practice.

The post-positivist approach where realist evaluation is embedded entails elements of all three perspectives (empirical, interpretivist and pragmatist approach, Kazi 2001) however; it differs in respect to how reality is viewed. Positivism concerns asingle, concrete reality that can be measured by a disengaged observer and interpretivism concerns multiple realities that are interpreted and re-interpreted by participants (Krauss 2005) and the realist ontology posits that there are multiple perceptions about a single reality and that reality exists independent of our interpretations of that world (Krauss 2005; Westhorp 2011).

Realist evaluation draws on the realist philosophical positions of science as espoused by Bhaskar, Harre, Putnam and others where realism is regarded as a post-positivist perspective that steers a path between empiricists and constructivists' accounts of scientific explanation (Pawson 2006). However, Maxwell $(2012,5)$ believes that the critical realists' view that there is a real world that exists independently of our perceptions accommodates the constructivists' interpretation that the understanding is inevitably a construction from perceptions and standpoint - a position he regards as an alternative to both naive realism and radical constructivists' views that deny the existence of any reality apart from our own constructions. He claims that critical realism's rejection of multiple realities is not incompatible with the 
constructivists' view since critical realism accommodates multiple constructions and perspectives. A substantial amount of qualitative research, according to Maxwell $(2012,10)$, is implicitly realist in its assumptions and methods.

Realism, as a philosophical paradigm therefore has elements of both positivism and constructivism and both quantitative and qualitative methodologies are seen as appropriate for researching the underlying mechanisms that drive actions and events. However, rather than being value-free, as in positivist research, or value-laden as in interpretivist approaches, realism is 'value cognizant'; conscious of the values of human systems and of researchers (Krauss 2005). Furthermore, critical realism differs from a 'naïve' or 'empirical' conception of realism by distinguishing between the 'real', the 'actual' and the 'empirical' - as a stratified ontology introduced by Bhaskar in1975 (Olsen 2010). Empiricism makes reference only to experience (the empirical) and that can be misleading as it relies on conceptual frameworks and conflates this with the real instead of separating them (Bhaskar 1979). The 'real' and the 'actual' as part of the critical realist ontology presuppose that not all the structures of the things that we experience may be in fact observable (Sayer 2000).

Realist evaluation is also regarded as a species of theory-driven evaluation (Cardin and Alkin 2012; Astbury 2013) that is of the view that all programmes are theory-laden, and that these theories hold the assumptions about how change is brought about through interventions. Pawson and Tilley (2004) agree with the similarity but assert that within realist evaluation the programme theory is specified in realist terms, that is, with a distinct philosophical orientation.

A realist approach assumes that programs are 'theories incarnate'. That is, whenever a program is implemented, it is testing a theory about what 'might cause change', even though that theory may not be explicit. One of the tasks of a realist evaluation is therefore to make the theories within a program explicit, by developing clear hypotheses about how, and for whom, programs might 'work'. (Pawson and Tilley 2004, 3)

The distinct philosophical orientation to programme theory is encapsulated in what Astbury (2013) refers to as the 'analytic centerpiece' of realist evaluation; that is the search for underlying mechanisms $(\mathrm{M})$ that in particular contexts $(\mathrm{C})$, generate outcomes $(\mathrm{O})$. Sometimes presented as a simple formula of Context + Mechanism $=$ Outcomes .

Mechanism refers to the way in which resources interact and describe what it is about programmes that bring about change. Pawson and Tilley (2004) maintain that it is not programmes that work but the resources they offer to enable their participants to make them work. Mechanisms are often hidden and should be made visible in the evaluation process. Mechanisms will be active in particular circumstances called the 'context'. These are features 
of participants, organization, staffing, history, culture etc.

For realism, it is axiomatic that certain contexts will be supportive to the programme theory and some will not. And this gives realist evaluation the crucial task of sorting the one from the other. Context must not be confused with locality. Depending on the nature of the intervention, what is contextually significant may not only relate to place but also to systems of interpersonal and social relationships, and even to biology, technology, economic conditions and so on. (Pawson and Tilley 2004, 7)

Outcome patterns generally emerge from programme implementation and they comprise the intended and unintended consequences of programmes. Instead of relying on a single measure of success, realist evaluators strive to understand and explain outcome variations through systematic theory testing and refinement (Astbury 2013). Kazi (2003) adds that the stratified ontology of realism includes the concept of 'emergence', meaning that the stratification of structures in the open system continually gives rise to new and emerging phenomena. This implies an awareness of the ever-changing contexts where social programmes are implemented. Whatever the outcomes, the realist evaluator will aim to identify how the programme mechanisms interacted to produce the outcomes and how the patterns of interrelationships may be transformed over time.

A brief overview of the action research intervention is provided below followed by an outline of the intervention in the LIS pilot site. An analysis of the context, that is, the conditions needed to trigger mechanisms (Gill and Turbin 1999), precedes the explicit and emerging mechanisms of the intervention and the resulting outcomes. Information from students and staff was obtained through surveys and interviews administered during 2013 and 2014. Anonymity was assured and the action research project applied for and received ethical clearance via the institutional research committee.

\section{THE OVERALL ACTION RESEARCH CONTEXT}

The action research intervention by the Division for lifelong Learning started from what appeared to be a simple problem. Opportunities for study by working students were declining. The study used 'flexible learning and teaching provision' as its focus to signal the provision of flexible or varied opportunities to students for learning. The project embraced a notion of a flexible pedagogy that provided students a choice in the pace, place and mode of their learning. One that was responsive to a diversity of students - both working and not working - and learning styles. Casey and Wilson (2005) assert that introducing flexible learning in this type of context is bound to be an iterative process and action research provides one way of getting 
information in an effective way to establish feedback loops on the process of change.

The proposed action research had four points of reference: the student, the university, the workplace, and profession from which students came. It aimed to show how lifelong learning opportunities, which were conceptualized and provided in flexible ways, could support innovation in learning and teaching in order to enhance successful access and success to learning by working people. At the same time it intended to highlight how innovative flexible provision challenged both the higher education institutions and workplaces to interrogate understandings and approaches to professional development.

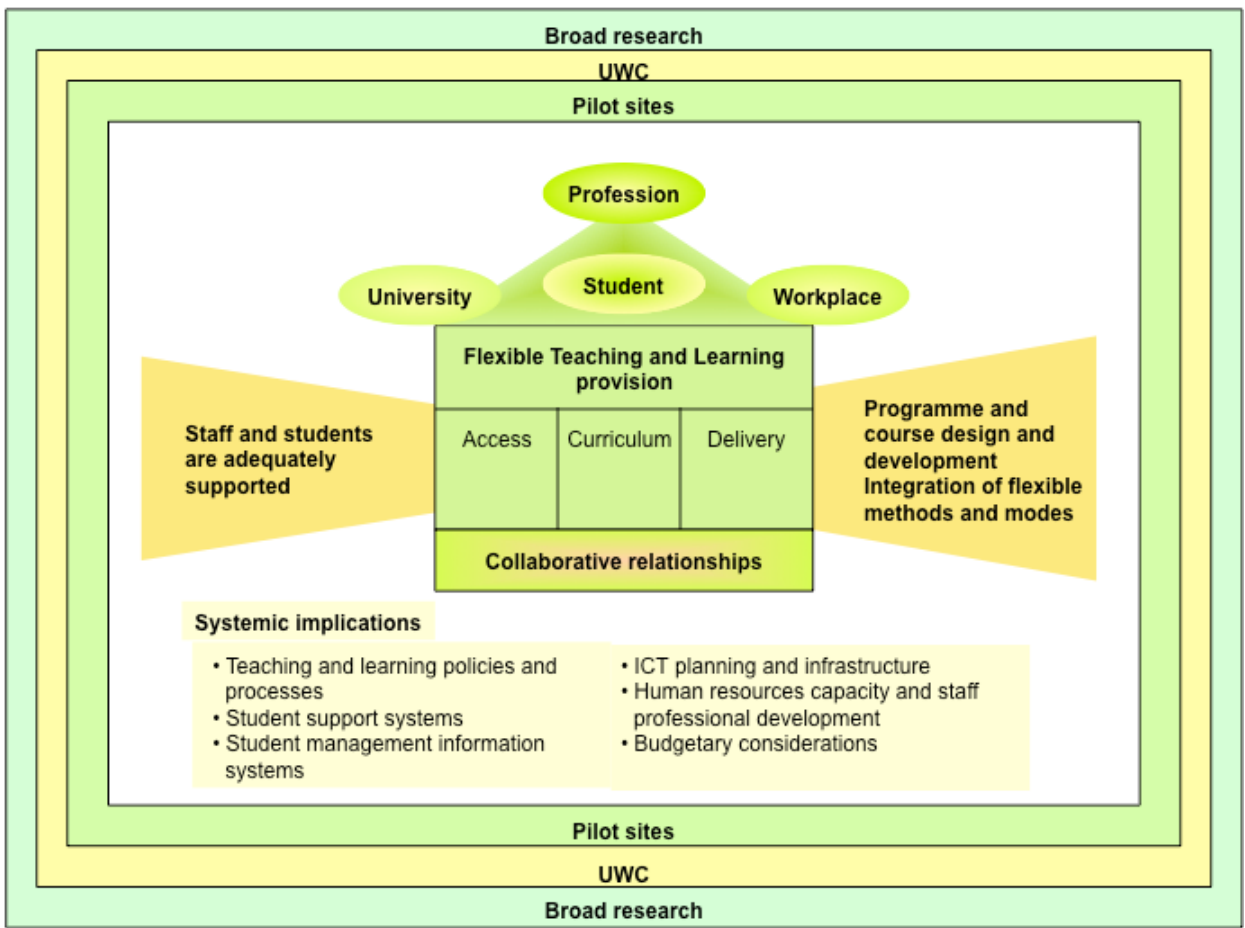

Programme Components 1 (DLL Strategic Plan 2012)

Figure 1: Programme components

Figure 1 outlines how DLL staff and site representatives viewed the interrelationships among components within the university. It projected systemic implications for the teaching and learning processes, student support systems and student management and information systems. There was upfront acknowledgement that any move towards introducing or strengthening flexible provisioning would have an impact on the kinds of resources, support, systems and processes needed to provide a stimulating and supportive learning and teaching environment (DLL 2012). After securing external funding the action research project was endorsed at the highest level of the institution and reporting structures were established to assist with institutionalization.

An enabling management structure was created consisting of a project committee for each 
pilot site, made up of representatives from the pilot sites and DLL. These committees reported to the DLL coordinating committee that provided overall direction to the project. A Senate Teaching \& Learning Advisory Committee (STLC) was established as a sounding board with representation from all faculties of the university as well as an external teaching and learning expert.

\section{LIS PILOT SITE - THE INTERVENTION}

One of the three pilot sites in the action research project was the Library and Information Science Department located in the Arts Faculty at UWC. The University of the Western Cape is the only university in the Western Cape region in South Africa offering undergraduate Library Science qualifications. The significance of this statement is amplified in the national context where there is a critical shortage of public libraries and an existing policy initiative to establish a library in every school. While the entire degree B.LIS, was the focus of the action research project, this article reflects on the assessment of initiatives towards more flexible learning and teaching strategies within the first-year semester course LIS111.

At the start of the project, full time students attended academic activities from 8:30 until 16:10 during weekdays, whereas part-time students typically attended to these activities from 17:00 until 20:20. The part-time students worked at the UWC or CPUT libraries as well as for the City of Cape Town Library Services (CoCT LIS). The latter category of students was allowed (10 days) 80 hours per annum to attend classes normally taking place during the day. They were usually practicing librarians (under-or unqualified) or some of them completed the Lower Diploma in LIS and wanted to improve their qualifications. They were generally more mature students while the full time students were normally straight from school. Because of the lack of availability of 'after-hours' courses, many of them attended courses of their choice during the day time.

The semester course LIS111 was taught with two lectures per week complemented by a weekly tutorial. The course content provided an overview of the development of writing, the alphabet, libraries, different types of information agencies and the link to mass media and publishing. The reading tutorials were introduced in 2008/9 when the faculty became concerned about the critical reading and academic writing skills of students. The tutorial aimed to get students to read widely, and to think critically about current LIS issues. Traditionally, the course material was made available as printed notes that students could purchase from the Arts Faculty Bookshop. LIS111 is also offered as an elective to BA general students who may or may not be interested to pursue librarianship as a profession or career. These students typically exit after 
the first-year, or possibly doing LIS121, another first year service course offered to Arts Faculty and Education Faculty students.

In 2013 the LIS111course materials were uploaded onto the Learning Management System (LMS), Ikamva. The printed format was totally abandoned. Students were required to access course notes, tutorial instructions and guidelines online. All announcements about class schedules, assessment dates and formats were posted online as well as on the notice boards located in the Department building. The 'announcement' feature allowed for rapid communication with students regarding course developments and students were notified via email. The 'resources' feature is the space where additional materials such as Power-point presentations and worksheets were deposited for students to access.

The students were required to access their course notes online in preparation for class. During class time, concepts would be clarified and explained using power-point presentations - also available prior to the class. The technology (online environment) allowed for quick searches to relevant and related materials. Students could experience the interactive nature of searching for information to enrich the curriculum. Students would then be referred to additional readings made available online. For the tutorials, the worksheets were made available beforehand and students were required to work through these in the computer laboratories when appropriate.

A blended learning approach was encouraged, founded on pedagogy that puts the student at the centre of learning. The action research project promoted flexible learning and teaching provision that included e-learning but did not equal e-learning. The latter has the opportunity to allow universities to extend their campus-based service to distant and online modes. Technology then, or e-learning was viewed as a medium, a means to achieve success and not an end in itself (Njenga and Fourie 2010) and this notion is supported by Crawford and Mckenzie (2011) who have studied the impact of local contexts on technology use and outcomes. They found that, instead of democratising the education process, the exclusive use of technology can exacerbate historical social inequalities.

The project was mindful of the context and did not assume that all students had access to the internet. Particularly since Statistics SA (2012) revealed that, on average, less than 10 per cent of South Africans have access to the internet at home, just over 5 per cent have internet access at school/college/university and that most people access the internet at work (just under 20\%). Flexible provision was understood as a broad provision of learning and teaching that encompassed a range of sustainable access, curriculum, and delivery variables that provided all students with the best chance of success (DLL 2012). 


\section{ANALYSIS OF THE CONTEXT}

The management structure of the action research project included a Senate Committee reporting to the Vice Chancellor, a Senate Teaching and Learning - Advisory Committee, with faculty representatives - where the DLL Coordinating Committee also reported and the Pilot Project Committees with representatives from the pilot sites. The locus of control for the project was however the DLL Coordinating Committee. The DLL initiated the project, secured the funding for the project, set up the subsequent structures for the management of the project and was responsible for reporting progress to the external funders. The project strategic plan projected the unfolding of the project in four phases. Phase 1 involved the setting up of the project, identifying project partners, entering into agreements with project sites, setting up structures, creating a conceptual understanding and developing a guiding framework. Phase 2 was concerned with mapping and innovating. The prevailing flexible provision and practices were mapped. Intervention strategies were implemented in pilot sites and project website was set up to collate resources and for communication. The $3^{\text {rd }}$ phase concerned the use of feedback from previous phases to improve practices and to implement innovations suggested by lessons of experience from others. The main focus of the $4^{\text {th }}$ phase was the consolidating of lessons and experience and promoting the necessary changes to policy and practice at institutional level (DLL 2012).

Pilot sites were identified based on the following criteria:

- A willingness of the faculty and departments to participate

- $\quad$ Pressure of increasing (part-time) student numbers

- A suitable undergraduate programme

- Possibilities for impact of the pilot for UWC's understanding and implementation of 'flexible provision'

- $\quad$ Capacity to deliver an entire undergraduate degree within a flexible provision framework

Factors that influenced the Library Information Science department to participate include LIS111 being identified as a 'killer course' by the faculty Teaching and Learning Committee and the recommended changes to tutorials during 2010. This means that that too many students failed the course and the recommendation was to increase the number of tutorials to one per week, instead of the fortnightly tutorial at the time. There was also a sharp decrease in the number of part-time students due the closing of part-time offering of OTHER courses in the 
faculty. Timetable clashes and limited subject choices also affected student numbers. Even fulltime students were forced to do an extra year because of timetable clashes. The LIS department also experienced a huge drop-off in student numbers over a three year period; for example in 2010, there were $1551^{\text {st }}$ year students and in 2013 there were 20 students for the $2^{\text {nd }}$ and $3^{\text {rd }}$ year modules. An incentive to participate in the action research project was the availability of R25 000 per year to be used by the department to support related activities - either through employing additional personnel, buying resources that would enable staff to better implement strategies or paying for training courses that would assist staff to improve their skills levels.

\section{The Learning Management System (LMS)}

Since 2005, UWC made use of an in-house, open source learning management system (LMS) called e-Teaching, built on the Chisemba platform. This LMS consisted of various teachingand-learning e-tools (i.e. content, communication and assessment). The uptake among staff was very limited primarily because of the unstable nature of the system. Staff and students complained about the numerous 'down-times' experienced. A new LMS (Ikamva), based on the Sakai platform, was introduced in 2012 and piloted in the LIS site. The roll-out occurred towards the end of 2013. This meant that the students participating in the action research intervention were exposed to the new LMS in LIS while still working on the existing eTeaching LMS in other courses.

\section{The students}

All the students, full- and part-time, registered for LIS111 were 'exposed' to the intervention. Those surveyed in 2013 all indicated that they were registered as full-time students. Despite this, 2 students indicated that they were working full-time and 5 were working part-time. Their times in employment ranged from 1 to 3 year (3 respondents) and 4 to 6 years (4 respondents). The following job titles were provided: Student assistant UWC; HR Student Development Assistant; Consultant; Trainee and Eskom librarian. The full-time 'registration' was an administrative requirement to enable part-time students to attend day-time classes.

Most of the students lived off campus - more than $15 \mathrm{~km}$ away from campus while relying on public transport to get to and from class. The majority (80\%) indicated that their studies were paid for via a National Student Financial Aid Scheme (NSFAS) loan or a bursary. Ninetyeight per cent of the respondents had exclusive access to a cellphone with only 2 per cent sharing. However, indications of no access to other technologies ranged as follows: 22 per cent desktop computer; 27 per cent laptop; 54 per cent broadband ADSL; 55 per cent WiFi; 60 per 
cent digital camera; 61 per cent Ipod/MP3; and 77 per cent tablet computer.

Most of them, 75 per cent, indicated that they mainly used their cellphone to access information on the web, with 40 per cent using it several times a day. While 22 per cent indicated that they used the web to access the learning management system (e-Teaching or Ikamva), 20 per cent indicated that they had not used the web to access these systems. On the other hand, some 60 per cent indicated that they used the web regularly to access general information for news and holidays.

A follow up survey was administered in 2014 to the same cohort of students. It should be noted that only one LMS (Ikamva) was available during this period. Here more students indicated that they had exclusive access to a desktop computer - 31 per cent compared to 16 per cent. More students had exclusive access to a laptop computer - 52 per cent, but the no access to WiFi or broadband ADSL remained similar to before. The cellphone remained the most popular means of accessing information. More than 50 per cent indicated that they used the web to access the LMS and 42 per cent were using it several times per day. There was also an increased use of the web for academic reference sources and for general use.

\section{EXPLICIT, STRATEGIC AND EMERGING MECHANISMS}

The first integrated mechanism introduced to facilitate the change process, was the availability of the monetary incentive for the department and their cooption onto the pilot project committee. This provided space for a staff member (co-author here) to spend time with the DLL staff to engage with the underlying thinking that informed the overall intervention and for ownership to be shared with the site.

This also resulted in a shift in the dynamics of the department itself. There was an early uptake of technology by one staff member - well before the action research intervention. The rest were very slow to embrace technology and reluctant to try out 'new' things. Since becoming a pilot site, there was more willingness to engage and staff members availed themselves for training in how to use the learning management system.

At the pilot project committee meetings, the department HoD and staff member reported on progress within the department, plans for using the 'incentive' grant, the challenges and future plans. These regular meetings ensured ongoing focused activity within the department. Besides reporting to the pilot project committee, the department also reported to their Teaching and Learning sub-committee in their faculty and reported on progress in their annual reports to faculty board meetings.

The learning management system Ikamva, was the key mechanism identified to engender 
flexible provisioning of the LIS111 course content. The LIS department pioneered the new system and made all course materials, including tutorial materials available online. All notes, presentations, worksheets and announcements could be accessed online. There were initial challenges; students having to deal with two different systems and the Ikamva system being off-line periodically during the piloting phase. However, the introduction of the new system was accompanied by the availability of training by the Centre for Innovative Educational and Communication Technologies (CIECT), responsible for the roll-out of the new system.

LIS staff members could also draw on the technological know-how of a colleague who had been experimenting with the online environment for a while. This staff member later became the head of the department and this entrenched the role, purpose and general thrust of the intervention.

During the early stage of the project, the DLL facilitated a meeting between the City of Cape Town (CoCT) Library officials and the LIS department. The meeting was called to discuss the CoCT's work-study policy that allowed for 80 hours per annum (during working hours) where staff could attend to their studies and access to computers at work. The working librarians used the allotted time to attend class or prepare for and write an examination. The implementation of the policy had been problematic for a number of students because in order to attend a two hour class, they had to travel four hours to and from campus. When it came to examination time, the students had little or no 'available' time and their managers did not allow them to use the computers at work for study purposes. This meeting and a subsequent meeting with the head of the human resources of the City of Cape Town, resolved that the work-study policy should be implemented as an enabling device, that is, managers should be more accommodating regarding the time used by the students, and students should be able to negotiate the use of available computers during mutually agreed periods. The outcome of this specific intervention was not assessed. However, staff members were asked to communicate the results to students.

The limited number of computers (17) in the dedicated LIS computer laboratory generally used by groups of 20, hampered application exercises and staff were compelled to work after hours and on weekends to accommodate students.

\section{OUTCOMES}

As a result of being part of the action research project and volunteering to pilot the new learning management system (Ikamva), all LIS staff members attended the training provided by the CIECT and were able to use the system to upload resources and communicate with students 
using the online environment. Staff members shared the following experiences during interviews:

Making materials/ information available online does not mean it will be used. Students still attend class not having read what is freely available online. Students were reluctant to the use discussion forum (DF) - even when marks were assigned. For most students English is their second language and they are/were not used to the discussion forum environment. (Staff interview; 8/9/13)

There is a need to experiment with available elements of the Ikamva system and make it more interactive (dynamic). The announcements work very well but students don't necessarily read their emails. (Staff interview; 2/10/13)

The system needs to allow for flexibility. Uploading marks for example should be less rigid. People/staff need time to develop their courses for FP and provide with time to think and do. Activities should be focused on both students and staff - but accommodate different types of students. (Staff interview; 2/10/13)

All the students had access to the resources made available online and the part-time students in particular benefitted by this arrangement as they felt that they were - for the first time - being treated equally to their full-time counterparts. The following feedback from students was obtained during the first survey in 2013:

The lectures were very informative and relevant to our course reader information, whereas the tutorials were fun and energetic, I enjoyed preparing for the discussion and debates in the tutorials. (Student feedback; 5/6/2013)

It was at times difficult to access the Ikamva site. Network connection should be improved. In some cases we had to submit our work late because we were struggling to get hold of the questions on Ikamva. (Student feedback; 5/6/2013)

It was difficult to access the account at home but after I copied the link I was able to gain access at home. I feel that this system will work fine if the access is more stable because there were times when I could not gain access to the site. (Student feedback; 5/6/2013)

I found downloading the workbook for LIS111 difficult because there wasn't an option to save the notes. I had to copy and paste into word. This was time-consuming and I would prefer if I could download the notes into a PDF. (Student feedback; 5/6/2013)

Some students volunteered to be interviewed about their online experiences and they shared the following: 
There must be more visual images like u-tube clips and videos. That will grab my attention. We are still like children, we are stimulated by pictures. Interestingly, that is what they teach us in the course. (Student interviews; 20/7/13)

They must give us laptops so that we can access work easily or to type assignments. Because now we use our cell phones and I have to wait at the computer lab for a turn to do my assignment. (Student interviews; 20/7/13)

The follow-up survey and interviews in 2014 produced mainly positive responses from both staff and students related to their experiences working in the online environment. This was because only one LMS was in operation, it was reliable, and was in use across the institution. A staff member reported the following:

The availability of physical space (classrooms) affected the timetable. The use of technology requires laboratory space, not lecture halls. In the Library department the computer labs are inadequate. There are limited resources, for example 17 computers for 20 in a class. (Staff interview; 3/5/2014)

Extrapolating from the interview responses (2014) with students, three distinct types of students emerged. Those who still prefer hardcopy or textbooks as a means to study and engage with course contents (30\%); those who encounter obstacles when attempting to engage with the technology, that is, they rely on access to computers, their notes and resources while on campus (40\%); and lastly, those who understand the importance of using technology as a tool to access resources and master course content through technology (30\%).

The availability of online resources (course notes etc.) did not replace the face-to-face class schedule or the tutorial offering. In the classroom, the online environment allowed for immediate searches and access to relevant sources pertaining to the concepts being discussed.

\section{DISCUSSION}

The intricate nature of the action research project is evident in its conceptualization of the challenges to implement innovative learning and teaching strategies provided in flexible ways that could enhance successful access and success to learning by working people. These attempts were initiated in an environment where institutional decisions about the use of facilities, resources and capacity generally favoured students who were residential and full-time (DLL 2012). There was recognition that contextual influences could hinder flexible provision and or provide opportunities to aid and support it.

The structural arrangements served to influence the mainstream discourse of teaching and 
learning at the institution - through engaging all students - while inserting the plight of working adults by involving workplaces as a strategy to interrogate understandings and approaches to professional development.

The monetary incentive to the pilot site LIS facilitated the space and opportunity for one staff member to develop a deeper understanding of project purposes that enabled her to act as a catalyst for innovation within the department. Through their cooption onto a project site committee the LIS staff was required to provide progress reports, future plans and to offer solutions to emerging challenges. These requirements influenced the dynamics and culture of staff meetings, interpersonal relationships, and practices of individual staff members. Initial resistance and reluctance among some staff members changed to compliance and later experimentation.

The unfolding programme theory of the overall action research project was imbued with a conception that all attempts at introducing innovative practices at the level of access, curriculum and delivery would be affected by and would have an impact on the kinds of resources, support and systems needed to provide a stimulating and supportive learning and teaching environment. Theorising at this level is a way, according to Pawson and Tilly (1997) to make evaluations 'cumulate'. The idea being to build up broad enough knowledge of the processes at work to have a fair chance of predicting what initiatives might have best chance of success in future interventions (Jolly, Crosthwaite and Brown 2009). The 'interdependencies' between the curriculum components; students and staff; learning, teaching and assessment processes; academic and administrative processes and procedures at the departmental and institutional level became obvious in this assessment.

Staff members in LIS, tasked to implement the online strategies initially resisted because they were required to utilize unfamiliar technology that was generally ignored across the institution because of its instability. In addition the intended use of the online environment was not accompanied by a reduction in contact time with students. The structural arrangements, referred to above, facilitated exposure training and a more positive attitude. The frustration experienced during the pilot phase of the new LMS slowed the momentum of the implementation.

The diverse student group was required to engage with two different learning management systems while battling to address and overcome their own limited technological exposure as well as learning styles. The working students were additionally constrained by time-factors, access to computers and institutional administrative arrangements that obliged them to register as full-time students. The limited number of computers available in the LIS computer 
laboratories also hampered access.

However, the more recent experiences of students, having to deal with only one learning management system, reveal a significant increase in the daily use of various technologies to access online academic resources, general announcements and additional documentation made available. More computer laboratory spaces will certainly enhance access. While the innovation 'mirrored' a blended learning course model, allowing students more flexibility about when, where, and how to access information, students were still required to attend the same number of face-to-face contact hours as stipulated in the institutional curriculum policy framework. As a pilot site, LIS should be allowed to experiment with the notion of contact hours for both classroom sessions and tutorials. This will result in a more creative use of technology, attention to student engagement with the content and innovative and meaningful ways of assessment. A reduction in the obligatory contact time will partially assist staff but will surely benefit working adults who have severe time constraints and a host of other responsibilities to deal with. The 'partial only' assistance for staff refers to the need for creative ways to be available to students in the online environment.

The complex, in some cases oppositional, institutional environment necessitated an integrated response in the form of introducing flexible learning and teaching strategies. The realist approach to this assessment allowed for the articulation of the context(s) in relation to explicit and emerging mechanisms that were used or operational during the intervention. It showed how the outcomes resulted from a dynamic interaction between explicit and emerging mechanisms and specific contexts.

\section{ACKNOWLEDGEMENT}

The action research project at the University of the Western Cape was financially supported by the South African Qualification Authority (SAQA).

\section{REFERENCES}

Astbury, B. 2013. Some reflections on Pawson's Science of Evaluation: A realist manifesto. Evaluation 19(4): 383-401.

Bhaskar, R. 1979. A realist theory of science. Brighton: Harvester.

Carden, F. and M. C. Alkin. 2012. Evaluation roots: An international perspective. Journal of Multidisciplinary Evaluation 8(17): 102-118.

Casey, J. and P. Wilson. 2005. A practical guide to providing flexible learning in further and higher education. Quality Assurance Agency for Higher Education (QAA). Edinburgh.

Clarke, A. and R. Dawson. 1999. Evaluation research: An introduction to principles, methods and practice. London: Sage Publications.

Crawford, N. and L. McKenzie. 201l. E-learning in context: An assessment of student inequalities in a 
university outreach program. Australasian Journal of Educational Technology 27(3): 531-545.

Daniels, E. K. and V. Roman. 2013. A descriptive study of the perceptions and behaviors of waterpipe use by university students in the Western Cape, South Africa. Tabacco Induced Diseases 11(4). http://www.tobaccoinduceddiseases.co./content/11/1/14 (accessed 20 September 2014).

DLL. 2012. Flexible learning and teaching at UWC: Strategic plan: 2013-2015. Bellville: University of the Western Cape.

February, C. and J. Koetsier. 2007. What support and success means to a group of working adults within one faculty as a South African Higher Education institution. Paper presented at the 5th International Conference on Research Work and Learning, Stellenbosch, 2-5 December.

Gill, M. and V. Turbin. 1999. Evaluating realistic evaluation: Evidence from a study of CCTV. In Surveillance of public space: CCTV, street lighting and crime prevention, ed. K. Painter and N. Tilley. Mounsey, NY: Criminal Justice Press.

Jolly, L., C. Crosthwaite and L. Brown. 2009. Building on strength, understanding weakness: Realistic evaluation and program review. 20th Australasian Association for Engineering Education Conference. University of Adelaide, 6-9 December.

Kazi, M. A. F. 2001. Realist evaluation in practice. Keynote address at the Thirteenth National Symposium on Doctoral Research in Social Work. Huddersfield, UK: 6 April.

Kazi, M. A. F. 2003. Realist evaluation in practice: Health and social work. Thousand Oaks: Sage Publications.

Krauss, S. E. 2005. Research paradigms and meaning making: A primer. The Qualitative Report 10(4): 758-770.

Maxwell, J. A. 2012. A realist approach for qualitative research. Los Angeles: Sage Publications.

Njenga, J. K. and L. C. H. Fourie. 2010. The myths about e-learning in higher education. British Journal of Educational Technology 41(2): 199-212.

Olsen, W. K. (ed.) 2010. Realist methods: Benchmarks in social research. London: Sage Publications. eScholar ID: 76425.

Pawson, R. 2006. Evidence-based policy: A realist perspective. London: Sage Publications.

Pawson, R. and N. Tilley. 1997. Realistic evaluation. London: Sage.

Pawson, R. and N. Tilley. 2004. Realistic evaluation. Paper funded by the British Cabinet Office. London.

Rossi, P. H., H. E. Freeman and M. W. Lipsey. 1999. Evaluation: A systematic approach. $6^{\text {th }}$ Edition. Thousand Oaks: Sage Publications.

Sayer, A. 2000. Realism and social science. London: Sage.

Statistics SA. 2012. October Household Survey. Pretoria: Statistics South Africa.

Westhorp, G. 2011. Realist evaluation: An overview. Report from an expert seminar. Centre for Development Innovation. Wageningen, the Netherlands. 